\title{
Research on the Correlation Between Carbon Performance and Enterprise Performance
}

\author{
Ziping Du \\ Research Center of Financial Engineering and Risk \\ Management \\ School of Economics and Management \\ Tianjin University of Science and Technology \\ Tianjin, China 300222
}

\author{
Genzhu Li \\ Research Center of Financial Engineering and Risk \\ Management \\ School of Economics and Management \\ Tianjin University of Science and Technology \\ Tianjin, China 300222
}

\begin{abstract}
Why do companies spend money to disclose these carbon information? From the perspective of internal economic motives, this paper attempts to select the Fortune 500 companies as samples, and use the OLS method to study the relationship between carbon performance and corporate performance from both the capital market and the product market. The results show that both carbon performance and corporate value are positively correlated in both the capital market and the product market, indicating the unification of carbon performance and corporate performance.
\end{abstract}

Keywords-carbon performance; market value; financial performance

\section{INTRODUCTION}

The hurricanes that occurred in the Atlantic last year, the wild wildfires in California, the monsoon anomalies in South Asia, the choking heat waves in Europe, and the lowest records of the Arctic winter sea ice are all deterioration of the global climate characterized by increasing greenhouse effect. Due to the occurrence of these anomalous climates, environmental issues have received unprecedented attention. The economic development model of "low energy consumption, low pollution, low emissions and high efficiency" has quickly gained the attention of the public. As an important part of economic and social development, enterprises are also the main source of greenhouse gas emissions, so their environmental information has been widely concerned by the government and people. In the past, research focused on environmental performance and financial performance, but there is little empirical research on the relationship between carbon emission reduction and corporate value [1]. Therefore, we select carbon emissions from environmental information and study the relationship between carbon performance and corporate value from both the product market and the capital market.

In terms of voluntary disclosure, the Carbon Disclosure Project (CDP) is a non-profit organization that operates global information disclosure systems for investors, businesses, buyers, and international organizations, cities, provinces/states, and regions and helps them manage environmental impacts, whose main purpose is to "create a lasting relationship between shareholder value caused by climate change and company operations." In view of the authoritativeness and comprehensiveness of CDP's assessment of carbon emission levels and carbon emissions information, we selected the Fortune 500 companies disclosed in the Carbon Disclosure Project (CDP) as research samples and used carbon emissions data to measure carbon performance. The main contributions of this research are reflected in the following three aspects. First, it expands from research on environmental behavior to research on carbon behavior; second, it measures enterprise value from the perspective of capital market and product market; third, the data sources used are from independent third-party reports, making data consistent and comparable and avoiding problems from self-selection in corporate annual reports

\section{LITERATURE REVIEW AND RESEARCH HYPOTHESIS}

Early research starts from the theory of agency and believes that the goal of enterprise managers is to maximize shareholder wealth rather than increasing social welfare, so that they found there is negative correlation between environmental performance and financial performance [2]. In recent years, most of the research focuses on the theory of stakeholders and the theory of social responsibility, which believe that enterprises' undertaking social responsibility can not only improve the reputation and image of the company, but also reduce the government's constraints on the enterprise [10]. Then it is found environmental performance has a positive impact on corporate value [3] [4]. Since Friedman (1970) first studied that the social responsibility information has value relevance [5], supporters Porter and Linde (1995) agree with the value effect of social responsibility [6], while Griffin and Mahon (1997), etc. has some doubts about the economic contribution of social responsibility [7]. Fujii et al. (2013) summarized the main points of previous scholars and came up with four relationships: positive correlation, negative correlation, Ushaped and inverted U-shaped [8]. With the development of the carbon emission reduction viewpoint, the carbon information (1) not only reveals the environmental risk, but also reflects the economic value, which increases the initiative of voluntary disclosure; (2) compared with the complexity of environmental information and difficulty in measuring, carbon information is quantified by using carbon 
dioxide emissions as an evaluation standard, which is comparable [9]. Due to these characteristics of carbon information, to some extent, the development prospects of carbon information are superior to environmental information, and the research on carbon information and carbon performance is also increasing. Just as the relationship between environmental performance and financial performance is still not concluded, the relationship between carbon performance and financial performance is not yet unified. Wang Zhiliang et al. (2013) have obtained positive effects on the improvement of enterprise value through empirical research [10]. Zhou Zhifang et al. (2017) believe that carbon performance is negatively correlated with financial performance in the short term [11].

On the one hand, according to the "Porter Hypothesis" and the relevant theory of stakeholders, the improvement of carbon performance can enhance the reputation of enterprises, reduce the government's constraints on corporate environmental control, gain the favor of investors, and then increase the value of enterprises from the perspective of capital market; On the other hand, the improvement of carbon performance will reduce energy consumption and waste discharge, reduce product cost and environmental treatment costs, and at the same time attract customers who are concerned about environmental issues, increase product sales, and then enhance corporate value from the perspective of product market. Thus, the hypothesis is proposed:

$$
\begin{aligned}
& M V_{i, t}=\alpha_{0}+\alpha_{1} C P_{i, t}+\alpha_{2} S I Z E_{i, t}+\alpha_{3} L E V_{i, t}+\alpha_{4} N P M_{i, t}+\alpha_{5} G R_{i, t}+\alpha_{6} B E T A_{i, t}+\alpha_{7} A T_{i, t}+\varepsilon_{i, t} \\
& T P_{i, t}=\beta_{0}+\beta_{1} C P_{i, t}+\beta_{2} S I Z E_{i, t}+\beta_{3} L E V_{i, t}+\beta_{4} N P M_{i, t}+\beta_{5} G R_{i, t}+\beta_{6} B E T A_{i, t}+\beta_{7} A T_{i, t}+\varepsilon_{i, t}
\end{aligned}
$$

The description and interpretation of the variables involved in the model are shown in "Table I". market value in the capital market
H1: Carbon performance is positively correlated with

$\mathrm{H} 2$ : Carbon performance and financial performance are positively correlated in the product market

\section{RESEARCH SAMPLES AND METHODS}

\section{A. Sample Selection and Data Source}

This paper selects the cross-sectional data of carbon emissions from the world's top 500 enterprises in the 20112013 in CDP project as the research samples, and excludes those that do not meet the requirements: (1) enterprises that didn't respond to the CDP questionnaire; (2) Companies without carbon emissions data for at least one year from 2011 to 2013; (3) companies that do not have complete financial data. A total of 543 observational samples were obtained, covering 10 industries including energy, industry, materials, utilities, daily consumption, optional consumption, finance, healthcare, information technology and telecommunications services. The raw data related to the company finance comes from the Wind database, and the data analysis is processed by STATA11.

\section{B. Research Models and Variable Interpretation}

TABLE I. DESCRIPTION AND DEFINITION OF VARIABLE INDICATOR

\begin{tabular}{lll}
\hline symbol of Variable & \multicolumn{1}{c}{ name of Variable } & \multicolumn{1}{c}{ description of Variable } \\
MV & Market value & Stock market value \\
TP & financial performance & total profit \\
CP & Carbon performance & operation revenue/carbon emission \\
SIZE & enterprise scale & natural logarithm of year-end total assets \\
LEV & Debt capacity & asset-liability ratio \\
NPM & Profitability & Sales net profit ratio \\
GR & Growth ability & growth rate of Operating income \\
BETA & Risk level & Annual comprehensive BETA value \\
AT & Operating capacity & Total asset turnover \\
\hline
\end{tabular}

\section{EMPIRICAL TESTING AND ANALYSIS}

\section{A. Descriptive Statistics}

"Table II" lists the statistical characteristics of the variables involved in the model. On the whole, the difference between the maximum and minimum of the indicators MV and TP for measuring enterprise value is large, indicating that there is a big gap between the values of enterprises. The average TP was 78.43 and the standard deviation was 141.3, indicating that the majority of the samples were concentrated between -62.87 and 219.73 . The average carbon performance is 87.88 , and the minimum is 0.028 , which indicates that there is a big gap between the carbon performance of enterprises, and this difference will in turn affect the performance of enterprises. This is the reason for our research. 
TABLE II. DESCRIPTIVE STATISTICS

\begin{tabular}{lrlrlrl}
\hline \multicolumn{1}{c}{ variable } & N & mean & sd & min & p50 & max \\
\hline MV & 543 & 7.305 & 12.04 & 0.767 & 4.016 & 159.3 \\
TP & 543 & 78.43 & 141.3 & -120 & 40.69 & 1400 \\
CP & 543 & 87.88 & 527.7 & 0.028 & 8.384 & 8600 \\
SIZE & 543 & 25.17 & 1.396 & 22.35 & 24.84 & 29.27 \\
LEV & 543 & 0.657 & 0.200 & 0.199 & 0.642 & 1.164 \\
NPM & 543 & 0.124 & 0.132 & -0.848 & 0.117 & 1.550 \\
GR & 543 & 0.077 & 0.190 & -0.511 & 0.050 & 2.973 \\
BETA & 543 & 0.854 & 0.988 & -0.092 & 0.801 & 21.85 \\
AT & 543 & 0.619 & 0.496 & 0.012 & 0.553 & 2.909 \\
\hline
\end{tabular}

\section{B. Correlation Analysis}

"Table III" shows the results of the correlation analysis between variables. According to the correlation results, it can be seen that $\mathrm{MV}$ and $\mathrm{CP}$ are significantly positively correlated at the $1 \%$ level, and there is a significant positive correlation between TP and $\mathrm{CP}$, which initially supports hypothesis 1 and hypothesis 2. For the control variables SIZE, NPM, and GR, they all have a positive impact on firm performance while LEV is negatively correlated with firm performance; BETA is positively correlated with MV and negatively correlated with TP; the relationship between AT and firm performance is opposite to the relationship between it and BETA. In addition, although the correlation coefficient between LEV and AT and SIZE both exceed 0.5, the multicollinearity test is further developed in the regression analysis to avoid the multicollinearity problem.

TABLE III. PERSON CORRELATION COEFFICIENT

\begin{tabular}{|c|c|c|c|c|c|c|c|c|c|}
\hline & MV & $\mathbf{T P}$ & CP & SIZE & LEC & NPM & GR & BETA & AT \\
\hline MV & 1 & & & & & & & & \\
\hline TP & $0.647 * * *$ & 1 & & & & & & & \\
\hline $\mathrm{CP}$ & $0.765 * * *$ & $0.425 * * *$ & 1 & & & & & & \\
\hline SIZE & $0.324 * * *$ & $0.359 * * *$ & $0.268 * * *$ & 1 & & & & & \\
\hline LEV & -0.011 & $-0.080^{*}$ & $0.155^{* * *} *$ & $0.570 * * *$ & 1 & & & & \\
\hline NPM & $0.115^{* * *}$ & $0.245^{* * *}$ & 0.014 & -0.013 & $\overline{0.151 * * *}$ & 1 & & & \\
\hline GR & 0.010 & $0.124 * * *$ & 0.050 & -0.035 & $\overline{-}-138 * * *$ & $0.129 * * *$ & 1 & & \\
\hline BETA & 0.017 & -0.051 & 0.039 & $0.227 * * *$ & $0.116^{* * *}$ & $\overline{0} .167 * * *$ & -0.034 & 1 & \\
\hline AT & -0.004 & 0.056 & $\overline{0.128 * * *}$ & $\overline{0.509 * * *}$ & $\overline{0.302 * * *}$ & $\overline{0.176 * * *}$ & 0.068 & $\overline{0.163 * * *}$ & 1 \\
\hline
\end{tabular}

a. Note: $* * *, * *, *$ indicate significant at $1 \%, 5 \%$, and $10 \%$, respectively.

\section{Regression Analysis}

In the empirical test of the correlation between carbon performance and firm performance, since the selected data is cross-sectional data that often has heteroscedasticity problems, the results will be inaccurate. Therefore, it is necessary to perform a White Test on the data to determine the presence or absence of heteroscedasticity. The results of White test show that the $p$ value is 0.000 , indicating the presence of heteroscedasticity. The data was processed by using "OLS+robust standard error" and the results are shown in "Table IV". From the results presented by model (1) and model (2) in "Table IV", it can be seen that the adjusted R2 is 0.7070 and 0.5072 respectively, and the significance level is 0.000 , indicating that the model has good fitting degree and high explanatory power and the equation is significant. In addition, the multi-collinearity test results show that the VIF values are less than 2, indicating that there is no multicollinearity problem between the variables. Specifically, in model (1), MV and $\mathrm{CP}$ are positively correlated at a significant level of $1 \%$, indicating that carbon performance does have an impact on market value. The better carbon performance is, the higher the market value will be. Hypothesis 1 is verified. In terms of control variables, SIZE, NPM, AT and MV are all significantly positively correlated, indicating that firm size, net sales margin, and total asset turnover have a positive impact on market value; LEV, GR and market value are significantly negatively correlated, which indicates that the high degree of debt and the fast growth rate are not conducive to the improvement of market value; the significance of BETA and MV is not obvious, showing a negative correlation, which is contrary to the preliminary conclusion drawn from the analysis of correlation results. In model (2), it can be seen from CP's coefficient of 0.0920 and $p$ value of 0.000 that $\mathrm{CP}$ and TP are significantly positively correlated, indicating that carbon performance plays a positive role in improving financial performance, and hypothesis 2 is verified. In terms of control variables, unlike the impact on market value, GR is positively correlated with financial performance, and the relationship between the remaining control variables and financial performance is the same as the market value in model (1). 
TABle IV. BAsic Regression Results of CARbon Performance ANd Market Value

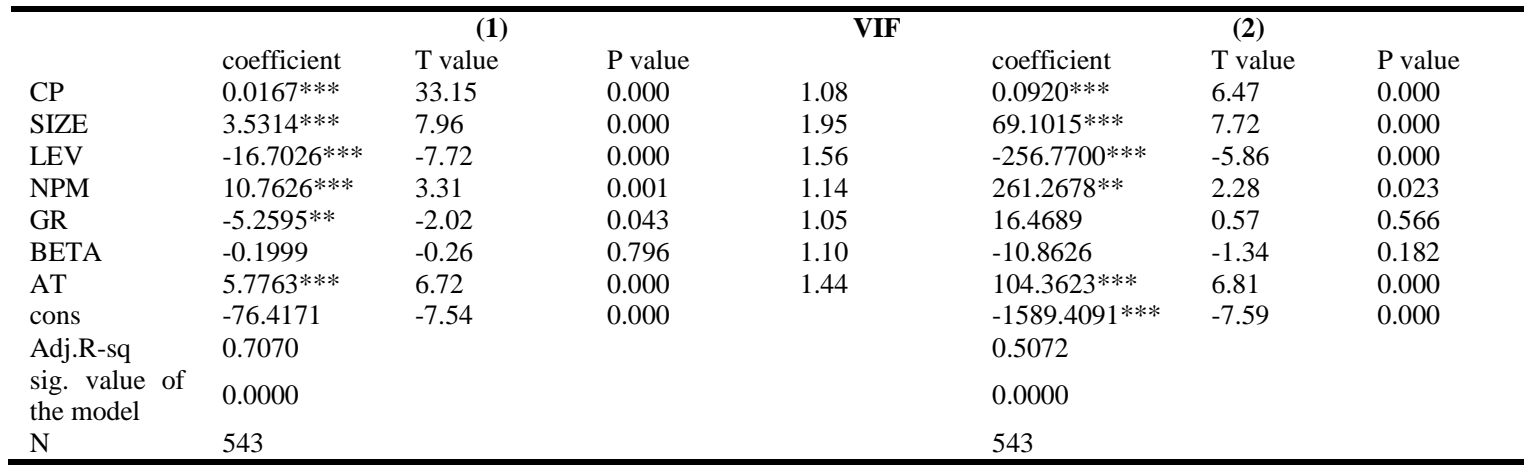

\section{Robustness Test}

The measurement of market value and financial performance in model (1) and model (2) is an absolute value indicator. In order to ensure the reliability of the result, the absolute value indicator MV used to measure the market value is replaced by the relative value indicator TobinQ and TP that is used to measure financial performance is replaced by the total asset turnover (ROA). The heteroscedasticity test and the multicollinearity test are still performed after the variables are replaced. "Table $\mathrm{V}$ " shows the adjusted data results. The data shows that in the model (1) where the market value is measured by TobinQ, the adjusted $R^{2}$ of the model is 0.3748 , and the $\mathrm{p}$ value is 0.0000 . The goodness of fit is decreased compared with the original and the significance is unchanged. The coefficient 0.0001 and the value 0.000 of the $\mathrm{CP}$ indicate that the carbon performance is significantly positively correlated with the market value (TobinQ), and the assumption 1 is established. In the model where financial performance is measured by ROA (2), the adjusted $\mathrm{R}^{2}$ of the model is 0.5494 , and the $\mathrm{p}$ value is 0.0000 . The degree of fitting is almost the same as before, and the equation is still significant. $\mathrm{CP}$ and ROA are positively correlated at a significant level of $1 \%$, indicating a significant positive correlation between carbon performance and financial performance (ROA).

TABLE V. ROBUSTNESS TEST

\begin{tabular}{|c|c|c|c|c|c|c|c|}
\hline & & (1) & & VIF & & (2) & \\
\hline & coefficient & $\mathrm{T}$ value & $P$ value & & coefficient & $\mathrm{T}$ value & $P$ value \\
\hline $\mathrm{CP}$ & $0.0001 * * *$ & 4.53 & 0.000 & 1.08 & $8.665 \mathrm{e}^{* * *}$ & 5.65 & 0.000 \\
\hline SIZE & $-0.3088 * * *$ & -8.07 & 0.000 & 1.95 & $-0.0135 * * *$ & -4.79 & 0.000 \\
\hline LEV & $0.5197 *$ & 1.95 & 0.051 & 1.56 & $-0.0405^{*}$ & -1.95 & 0.051 \\
\hline NPM & $1.9726 * * *$ & 3.65 & 0.000 & 1.14 & $0.2666^{* *}$ & 3.11 & 0.002 \\
\hline GR & -0.1062 & -0.79 & 0.430 & 1.05 & 0.0203 & 1.33 & 0.184 \\
\hline BETA & $0.0441 *$ & 1.85 & 0.065 & 1.10 & $0.0052 * *$ & 2.41 & 0.016 \\
\hline AT & $0.5810 * * *$ & 5.60 & 0.000 & 1.44 & $0.0757 * * *$ & 8.83 & 0.000 \\
\hline cons & 8.4701 & 9.53 & 0.000 & & $0.3797 * * *$ & 5.52 & 0.000 \\
\hline Adj.R-sq & 0.3748 & & & & 0.5494 & & \\
\hline sig. value of the model & 0.0000 & & & & 0.0000 & & \\
\hline $\mathrm{N}$ & 543 & & & & 543 & & \\
\hline
\end{tabular}

a. Note: $* * *, * *, *$ indicate significant at $1 \%, 5 \%$, and $10 \%$, respectively, and $\mathrm{t}$ value is adjusted by stable standard error

\section{CONCLUSION}

This paper selects and analyzes the relationship between carbon performance and firm performance by selecting carbon emission data of Fortune 500 companies in the 20112013 CDP projects. Enterprise performance is described from the perspectives of capital market and product market. The study found that carbon performance is not only significantly positively correlated with market value in the capital market, but also significantly correlated with financial performance in the product market. This result means that because carbon performance is positively correlated with market value, investors in the capital market will include carbon performance when making investment decisions, while carbon performance involves the company's carbon reduction and even climate change strategy, so investors are not only concerned about the economic benefits of enterprises like before, but also pay attention to climate change issues and pay attention to the social benefits of enterprises. Therefore, taking a green development path and adopting a positive climate change strategy can help enterprises to obtain sustained economic benefits; on the other hand, the improvement of carbon performance helps enterprises to establish the image of green enterprises. This image will give consumers the impression of green environmental protection, and consumers are willing to spend more on green products, thus improving financial performance. 
The study has two limitations. First, the selected samples are all among the top 500 companies in the world. These companies are generally large in scale and may have scale bias. The conclusions drawn in this paper can be extended to large enterprises, but for SMEs, there may be deviations; due to the availability of data, carbon emissions data is only data in Scope 1, and does not involve carbon emissions in Scope 2 and Scope 3.

\section{REFERENCES}

[1] Prakash R, Matsumura E M, Veramunoz S C. Voluntary Disclosures and the Firm-Value Effects of Carbon Emissions[J]. Accounting Review, 2011, 89(2):695-724.

[2] Bai C, Sarkis J. Integrating sustainability into supplier selection with grey system and rough set methodologies[J]. International Journal of Production Economics, 2010, 124(1):252-264.

[3] Guenster N, Bauer R, Derwall J, et al. The Economic Value of Corporate Eco-Efficiency[J]. European Financial Management, 2011, 17(4):679-704.

[4] Yin J, Zhang Y. Institutional Dynamics and Corporate Social Responsibility (CSR) in an Emerging Country Context: Evidence from China[J]. Journal of Business Ethics, 2012, 111(2):301-316.

[5] Friedman M. The Social Responsibility of Business Is to Increase Its Profits[J]. New York Times Magazine, 1970, 13(6):173-178.

[6] Porter M E, Linde C V D. Toward a New Conception of the Environment-Competitiveness Relationship[J]. Journal of Economic Perspectives, 1995, 9(4):97-118.

[7] Griffin J J, Mahon J F. The Corporate Social Performance and Corporate Financial Performance Debate: Twenty-Five Years of Incomparable Research[J]. Social Science Electronic Publishing, 1997, 36(1):5-31.

[8] Fujii H, Iwata K, Kaneko S, et al. Corporate Environmental and Economic Performance of Japanese Manufacturing Firms: Empirical Study for Sustainable Development[J]. Business Strategy \& the Environment, 2013, 22(3):187-201.

[9] Ans Kolk, David Levy, Jonatan Pinkse. Corporate Responses in an Emerging Climate Regime: The Institutionalization and Commensuration of Carbon Disclosure[J]. European Accounting Review, 2008, 17(4):719-745.

[10] Wang Zhiliang, Jiang Zhifang. Research on the Relationship between Low Carbon Performance and Enterprise Order Value[J]. Commercial Accounting, 2013(23): 13-15.

[11] Zhou Zhifang, Xiao Wei, Zeng Huixiang. Research on the Correlation between Corporate Carbon Performance and Financial Performance - Evidence from the British FTSE 350 Index[J]. Journal of China University of Geosciences(Social Sciences Edition), 2017(5): 32- 43.

[12] Liu Ping, Chen Su. Research on the relationship between carbon performance and market performance in the automotive industry [J]. Macroeconomic Management, 2017(s1).

[13] He Yu, Tang Qingliang, Wang Kaitian. Carbon Performance and Financial Performance [J]. Accounting Research, 2017(2): 76-82. 